\title{
A INVERSÃO DAS MÁXIMAS EM OS MEUS SENTIMENTOS, DE DULCE MARIA CARDOSO
}

\author{
Mestranda em Estudos Literários FCLAr/Unesp \\ gabrielaborborema@live.com
}

Gabriela Cristina Borborema Bozzo

\section{RESUMO}

A inversão das máximas apresenta-se em Os meus sentimentos como ferramenta para desnudar a realidade sócio-histórica portuguesa. Procuramos investigar a máxima, a sua inversão e averiguá-la em nosso corpus. Para tanto, embasamo-nos em três linhas de estudo: o projeto artístico da escritora, com Liquidez, reconfigurações e pluralidades: $a$ representação identitária da sociedade portuguesa em $O$ chão dos pardais, de Dulce Maria Cardoso, de Gonçalves Neto e Gama; a máxima, com $A$ máxima; suas variedades, seu emprego, sua utilidade, de Aristóteles, La Rochefoucauld: reflexões ou sentenças e máximas, de Barthes, e $A$ Ciropédia de Xenofante: um romance de formação na Antiguidade, de Cerdas; e a inversão da máxima com The american face of Aesop: Thurber's Fables and Tradition, de Carnes.

Palavras-chave: máxima, projeto artístico, Os meus sentimentos, Dulce Maria Cardoso.

\begin{abstract}
The maxims' inversion apears in Os meus sentimentos as a tool to bare the portuguese social and historical reality. The purpose is to investigate the maxim, its inversion and verify it in our corpus. Therefore, three directions of study are taken: the writer's artistic project, in Liquidez, reconfigurações e pluralidades: a representação identitária da sociedade portuguesa em $O$ chão dos pardais, de Dulce Maria Cardoso, by Gonçalves Neto and Gama; the maxim itself, in A máxima; suas variedades, seu emprego, sua utilidade, by Aristóteles, La Rochefoucauld: reflexões ou sentenças $e$ máximas, by Barthes, and A Ciropédia de Xenofante: um romance de formação na Antiguidade, by Cerdas; and the maxim's inversion in The american face of Aesop: Thurber's Fables and Tradition, by Carnes.
\end{abstract}

Keywords: maxim, artistic project, Os meus sentimentos, Dulce Maria Cardoso.

\section{INTRODUÇÃO}

A produção literária de Dulce Maria Cardoso apresenta minucioso trabalho com a forma, cuja particularidade chega ao ápice em Os meus sentimentos (2012). O romance intriga o leitor pela ironia no discurso da narradora-personagem, que contesta verdades absolutas que compõem a realidade sócio-histórica representada na narrativa - a Revolução 
dos Cravos e os períodos que a circundam. Os acontecimentos do dia do acidente automobilístico da personagem são narrados em seis capítulos, em ordem invertida. A história de vida dela é contada através de anacronias. Nos quatro capítulos seguintes, é narrada a suposta morte da personagem e a continuidade da vida dos demais personagens. No último capítulo, Violeta parece encontrar a paz após desabafar os sentimentos que nomeiam o livro.

A partir do tema proposto - o estudo da inversão de máximas -, buscamos investigar como a inversão se dá no discurso; de que forma o caráter imoral de Violeta e a ironia contribuem para o questionamento do que era tido como verdade; e de que forma a inversão de máximas no romance corrobora na realização do projeto artístico - proposto por Gonçalves Neto e Gama em O chão dos pardais (2014), outra obra de Cardoso .

Para tanto, apresentamos o projeto artístico, abordando as questões sócio-históricas por ele implicadas e sua projeção na produção cardosiana; definimos o que são as máximas e o seu funcionamento no discurso narrativo; apresentamos o empréstimo das narrativas tradicionais e questionamento delas de James Thurber; por fim, averiguamos como funciona a inversão de máximas em Os meus sentimentos, como elas estão atreladas à ironia de Violeta e relacionando-as ao projeto artístico.

O embasamento teórico é formado por três linhas principais: (1) as proposições teóricas sobre a composição da narrativa da escritora formuladas em Liquidez, reconfigurações e pluralidades: a representação identitária da sociedade portuguesa em $O$ chão dos pardais de Dulce Maria Cardoso (2012), de Gonçalves Neto e Gama; (2) o estudo das máximas: A máxima; suas variedades, seu emprego, sua utilidade (1982), de Aristóteles; La Rochefoucauld: reflexões ou sentenças e máximas (1974), de Barthes; e A Ciropédia de 
Xenofante: um romance de formação na Antiguidade (2011), de Cerdas; (3) o estudo da inversão da matéria original de estruturas narrativas tradicionais em The american face of Aesop: Thurber's Fables and Tradition (1988), de Carnes.

\section{O PROJETO ARTÍSTICO DE DULCE MARIA CARDOSO}

O projeto artístico foi proposto por Gonçalves Neto e Gama tendo O chão dos pardais - outro romance da escritora - como corpus. Através de um discurso irônico focado na vida cotidiana de pessoas comuns, os autores propõem que a escritora desmascara a falsidade enquanto constrói as personagens e o discurso. O caráter do projeto artístico busca, nesse sentido, "desmistificar o sujeito português e aproximá-lo de sua realidade, desmistificando-a" (GONÇALVES NETO; GAMA, 2012, p. 1).

A falsidade desmascarada refere-se ao acontecimento que marcou a história portuguesa recente: a Revolução dos Cravos. Apesar de datas não serem aludidas diretamente nos romances, no início de $O$ chão dos pardais, a morte da princesa Diana, que ocorreu em 31 de agosto de 1997, é noticiada na TV. Nesse romance, Violeta, narradoraprotagonista de Os meus sentimentos, é vista por dois personagens no metrô depois de seu acidente. Logo, as narrativas se passam na segunda metade de 1997:

Faltavam duas estações para o destino deles, quando uma mulher se sentou ao lado de Sofia, uma mulher muito gorda, com o cabelo molhado, apesar do dia bonito de fim de Verão. Cheirava a tabaco e a cerveja e carregava dois sacos. Sofia espreitou para os sacos, com a mania de olhar para dentro de tudo, e viu várias amostras de ceras depilatórias. Sofia calou-se. Não queria que a mulher os ouvisse. Apesar do calor a mulher vestia collants e Sofia reparou que tinham uma malha caída. A mulher atenta ao olhar de Sofia disse: Foi por causa do acidente (CARDOSO, 2014, p. 92). 
A configuração social portuguesa em $O$ chão dos pardais, afirmam os autores, continua a mesma vinte e três anos depois. O que foi combatido pela revolução ainda está vigente. A personagem Sofia, amante do empresário casado Afonso, para Gonçalves Neto e Gama (2012, p. 2), é a metáfora desse “[...] Portugal decadente que o estado se tornou depois do 25 de Abril: um país falso, prostituído e mentiroso."

O matrimônio de Afonso e Alice é interpretado por Gonçalves Neto e Gama (2012, p. 3) como uma metáfora da família tradicional portuguesa decadente, que é regida por aparências, traições e mentiras. A crítica circunscrita no romance, para os autores, também é antirreligiosa, o que atinge um dos grandes pilares da configuração social portuguesa.

O indivíduo português hodierno é metaforizado em Manuel, filho do casal, a única personagem que sai da zona de conforto, demonstrando o direito à utopia no horizonte desse sujeito. A utopia, contudo, não se concretiza: quando Manuel encontra sua namorada virtual, resta, entre ambos, a solidão. O encontro "[...] demonstra, alegoricamente, o grande problema do sujeito português (e, por que não dizer, humano) da contemporaneidade: o desconhecimento medroso do outro e a importância do mesmo para a formação do eu" (GONÇALVES NETO; GAMA, 2012, p. 4).

Logo, mesmo após a Revolução, “[...] a família continua a ser tradicional, o machismo ainda impera e a igreja continua a ditar os princípios morais da sociedade, que esconde suas impudicícias atrás de uma realidade morta" (GONÇALVES NETO; GAMA, 2012, p. 5). O intuito almejado no 25 de Abril ainda não foi alcançado, o que é desmascarado por Cardoso: "[...] toda a sociedade passa pelo pente fino da análise irônica da escritora [...]" (GONÇALVES NETO; GAMA, 2012, p. 5). 
A epígrafe de $O$ chão dos pardais - "Y yo que me sabía pobre, de una pobreza sin nombre. $Y$ triste, de uma tristeza sin derechos, sin quejas y sin fin, rasgué mi ropa y les mostre mi herida" (LOYNAZ apud CARDOSO, 2014, p. 7) - para Gonçalves Neto e Gama (2012, p. 5) é uma indicação indireta de seu intuito: desmascarar a sociedade portuguesa e deixar sua podridão exposta.

Acreditamos que essa epígrafe também se relaciona com a dificuldade do indivíduo de comunicar-se, apresentada na negação da utopia a Manuel. $O$ medo e o desconhecimento do outro, bem como a importância desse outro para a formação do eu, como afirmaram Gonçalves Neto e Gama (2012, p. 4), são os grandes desafios do sujeito hodierno, não só português. A epígrafe parece contrastar com o medo do contato com o outro, a solidão e o excesso de individualidade que são criticados no discurso irônico de $O$ chão dos pardais. Nesse romance, uma narrativa que direciona seu leitor a se posicionar criticamente frente aos acontecimentos de seu tempo é elaborada: “[...] o embate presenciado em 74 precisa continuar a acontecer para que suas sementes sejam plantadas, e não esquecidas" (GONÇALVES NETO; GAMA, 2012, p. 5).

A escritora, como afirmam Gonçalves Neto e Gama (2012, p. 7), traz o olhar descentralizante a fim de formar o leitor consciente e crítico, que é o seu outro: “É a autora a exigir que o outro, seu elemento de alteridade, se torne presente e aja." A ironia de Cardoso desmascara a realidade social portuguesa e, após a leitura, "o leitor cardosiano nota que há uma grande diferença entre aquilo que dizem ser a verdade, mas é só aparência e a essência da sociedade" (GONÇALVES NETO; GAMA, 2012, p. 7).

\section{DA PARÊMIA À MÁXIMA}


A parêmia, segundo Monteiro-Plantin (2017, p. 2), é um termo geral que compreende ditos populares, provérbios, frases feitas, aforismos, refrões, aforismos e máximas. As sentenças proverbiais, como Monteiro-Plantin (2017, p. 3) denomina as parêmias, têm como principal característica a transmissão de um ensinamento, conselho ou lição. Dentre as parêmias mencionadas pela autora, destaca-se no nosso artigo a máxima.

A máxima é, para Aristóteles (1982, p. 146), um discurso conciso que expressa uma perspectiva de mundo universal. O prazer do ouvinte da máxima, propõe Aristóteles (1982, p. 148), vem da sua satisfação com um discurso que apresenta um saber - compreendido por ele antes num caso particular - em termos gerais. O caráter moral do orador está relacionado ao perfil de quem profere as máximas, definido por Aristóteles (1982, p. 147148): a capacidade de persuasão do discurso da máxima depende do caráter do orador. Ele costuma ser alguém mais velho e mais experiente, e o uso de máximas e fábulas por alguém que não atingiu a velhice é considerado estúpido. Ademais, o ensinamento da máxima será recebido pelo público como verdadeiro se o orador tiver experiência no assunto discursado. Já o caráter moral da máxima:

existe sempre que se manifestam as preferências do orador. Todas as máximas produzem esse efeito, pois quem as utiliza mostra de maneira geral quais são as suas preferências; por conseguinte, se as máximas são honestas, farão com que o caráter do orador pareça igualmente honesto (ARISTÓTELES, 1982, p. 148)

A máxima é formada, de acordo com Barthes (1974, p. 11; 24-25), por um saber condensado acerca da natureza humana, constituindo um tipo de discurso moralizante. Cerdas (2011, p. 186) afirma: 
Portanto, a máxima é um estilo de discurso ligado à percepção do mundo, que ajuíza sobre o comportamento humano e sob o qual transparece os valores estéticos e morais de uma sociedade.

As máximas podem existir no discurso romanesco: de acordo com Cerdas (2011, p. 188), nesses casos, uma estrutura fabular é construída na narrativa, propiciando o surgimento de máximas. No romance, a máxima torna-se uma importante ferramenta de caracterização da personagem, pois “[...] manifesta o caráter da personagem, as suas preferências de comportamento social, seus anseios e objetivos ético-morais" (CERDAS, 2011, p. 182). Ela transmite a ideia da personagem, fundamental na caracterização. Além disso, as máximas "[...] propiciam a formação da personagem, uma vez que elas transmitem o caráter da personagem" (CERDAS, 2011, p. 183), seguindo o que propôs Aristóteles (1982, p. 148).

\section{A INVERSÃO DE MÁXIMAS}

De acordo com Carnes (1988, p. 312), a estrutura utilizada nas fábulas de James Thurber, fabulista norte-americano consagrado pelo humor satírico, é superficialmente a da fábula e do conto de fadas. Desse modo, as fábulas de Thurber apresentam uma narrativa curta, seguida por uma moral (epimítio), utilizando, assim, a estrutura fabular mais básica. 0 epimítio em Thurber é composto por um anti-provérbo. A inversão dos provérbios e ditados traz um realismo à narrativa do autor, o que é raro na fábula original.

Através do uso da estrutura fabular, Thurber coloca em questão a validade desse gênero literário, como propõe Carnes (1988, p. 315). O escritor refere-se à fábula dentro de sua fábula para argumentar ao seu leitor que ele não deve confiar nessas histórias. Através da paródia, ele utiliza o próprio gênero para desacreditá-lo. 
Ainda segundo Carnes (1988, p.326), uma anti-fábula é criada por Thurber. Esse, pautando-se na estrutura fabular, utiliza sua função - instruir o leitor - para negar a existência de uma sabedoria coletiva na sociedade. A utilização da fábula para negar a sua validade e sabedoria é um paradoxo: negar a existência de conselhos para a vida utilizando um gênero literário cuja função é oferecer essa assistência é o grande paradoxo da sua obra. Portanto, Thurber faz uso da fábula e de outros gêneros tradicionais, como o folclore e o conto de fadas, para demonstrar ao seu leitor a impotência desses textos em servir como guia para enfrentar os desafios da vida.

O uso da fábula por Thurber é como o uso da máxima por Cardoso: eles utilizam a estrutura superficial da fábula e da máxima, respectivamente, com as funções dessas estruturas invertidas. A máxima mantém a estrutura superficial na narrativa de Cardoso, mas apresenta seu propósito - reafirmar valores de uma sociedade - invertido, assim como a anti-fábula de Thurber descredita o poder de instrução dessa narrativa. Desse modo, a máxima invertida de Cardoso é como o anti-provérbio do epimítio de Thurber.

\section{OS MEUS SENTIMENTOS}

“Inesperadamente / não devia ter saído de casa, não devia ter saído de casa, não devia ter saído de casa, durante algum tempo, segundos, horas, não sou capaz de mais nada [...]" (CARDOSO, 2012, p. 9). Assim inicia-se Os meus sentimentos. O romance apresenta uma narrativa sensível e instigante centrada na narradora-personagem, Violeta, uma mulher obesa que não se enquadra nos padrões comportamentais e estéticos esperados pela sociedade em que (não) está inserida. 
A personagem narra, embriagada, que sofreu um acidente automobilístico durante a madrugada, na rodovia, e encontra-se de cabeça para baixo presa pelo cinto de segurança no carro. Temos a sensação de que o tempo parou para ela: "os olhos pousados, inertes, na gota de água cheia de luz, uma gota inundada de luz" (CARDOSO, 2012, p. 10). Tendemos a acreditar que a personagem está assistindo (e contando-nos) ao filme da sua vida nesse momento de incerteza, possivelmente entre a vida e a morte.

O acidente da personagem, que é apresentado no capítulo primeiro, é retomado frequentemente na narrativa, como se lembrasse ao leitor que tudo não passa da exposição de seu (in)consciente. A personagem narra, do capítulo segundo ao sexto, a sucessão inversa de acontecimentos daquele dia: a perda do controle da direção, a parada na loja de conveniência, a parada no posto para a caça aos caminhoneiros, o jantar com Dora (sua filha) e Ângelo (seu meio-irmão e pai de sua filha), a venda da casa de seus pais no banco, a última visita à casa. Do sétimo ao décimo capítulo, Violeta narra cronologicamente a sua suposta morte, resgate e a continuidade da vida de Dora e Ângelo.

No último capítulo da obra, o décimo primeiro, para nós a personagem não morreu, mas sim encontrou a paz após colocar para fora seus angustiantes sentimentos. O encontro com a luz - "rolo pela luz / rolo pela luz, docemente, a estrada é estreita" (CARDOSO, 2012, p. 367) -, não se trata de sua morte, mas sim da morte da dor e dos fantasmas. A luz também refere-se à sensação de leveza que contar suas angústias lhe trouxe: o peso do passado torna-se leve quando vive, sente e se desapega da dor. Ademais, a personagem menciona sua posição no carro, no nono capítulo, quando já havia narrado a própria morte, no sétimo capítulo: "[...] parada nessa posição esquisita o tempo mostra-se como nunca o 
tinha imaginado, dentro dos meus ouvidos grilos, gri-gri gri-gri, os olhos cegos por uma gota de luz." (CARDOSO, 2012, p. 317).

A narrativa é bastante distinta quanto à estrutura. $\mathrm{O}$ romance - composto por um único período, pontuado apenas por vírgulas e interrompido frequentemente por bordões definiu o estilo de escrita da escritora, como afirma em entrevista:

$\mathrm{E}$ [Os meus sentimentos] determinou o meu método criativo, que é o mais maluco. Porque o perdi. [...] Foi em 2004, para aí. Recebi um e-mail com um palhaço e cliquei no nariz. No dia seguinte tinha o computador todo preto. [...] eu, que ainda era casada na altura, disse ao meu marido: ou esqueço isto, esqueço a Violeta de vez, ou reescrevo de memória, enquanto está fresco. [...] E agora faço sempre isso: apago tudo. Já tentei não o fazer, mas não fica bem. É horrível, mas assim só fica o que me parece essencial (CARDOSO apud BOM, 2016).

\section{O PROJETO ESTÉTICO E A INVERSÃO DAS MÁXIMAS EM OS MEUS SENTIMENTOS}

A estrutura da máxima é utilizada no discurso narrativo de Os meus sentimentos, pois os bordões de Cardoso assumem, muitas vezes, a função e a estrutura da máxima no romance. Os bordões apresentam um discurso conciso que expressa uma perspectiva universal de mundo, que é apresentada depois de ilustrá-la em um caso particular. Uma estrutura fabular é criada no romance.

A máxima "a quantidade de coisas de que as pessoas se convencem que precisam" (CARDOSO, 2012, p. 113) é precedida das divagações de Violeta enquanto espera os compradores da casa de seus pais, falecidos recentemente, no banco. Ela observa o funcionário a sua frente e imagina a sua vida, a vida de seu chefe e a vida do chefe do seu chefe. É interessante notar que os três não têm nomes, aproximando-se da estrutura fabular - com animais antropomorfizados - invertida, pois em Os meus sentimentos, o recurso é para tipificar ao invés de individualizar. A perspectiva da personagem é pessimista, segundo 
a qual as pessoas trabalham em função de manter um padrão de vida cada vez mais elevado, o que torna a rotina um fardo necessário para bancar os gastos criados. Ela divaga:

[...] o funcionário até podia admitir que detesta o que faz se isso não o revoltasse mais, não fosse a troca do apartamento, o carro novo da mulher, o computador da filha mais velha, o infantário do mais pequeno, as férias de verão, e ninguém o obrigava a levantar-se cedo para se sentar a uma secretária a recolher informações enfadonhas sobre anónimos tão enfadonhos como as informações a que dão origem, o funcionário ficava a dormir todas as manhãs ou partia num cargueiro e dava a volta ao mundo, quando era novo sonhou com isso [...] (CARDOSO, 2012, p. 111).

A personagem atribui aspectos cada vez mais complexos aos motivos que levam as pessoas a viverem uma vida que odeiam. Ela passa a refletir sobre a rotina do chefe do funcionário, que diferente dele, não trabalha no open space, mas, sim, no andar de cima, num gabinete fechado. Violeta imagina:

[...] o chefe do funcionário aborrece-se com os pedidos de crédito monótonos que anónimos igualmente monótonos fazem, não fosse a casa de férias, o monovolume novo, o patrocínio do filho velejador, as viagens da filha poliglota, e ninguém o obrigava a levantar-se todas as manhãs para se enfiar neste gabinete, apesar da secretária e da cadeira regulável, do computador mais potente e da central telefónica, o chefe do funcionário dedicava-se à agricultura biológica, em novo quis ser agricultor e preocupa-se com os nitratos nos legumes, o chefe do funcionário assina os pedidos de crédito e coloca-os em pastinhas com capas transparentes [...] (CARDOSO, 2012, p. 112).

Por fim, a imaginação chega ao chefe do chefe do funcionário, que trabalha no piso acima, num gabinete maior e com vista. A tese é que quanto maior o salário, a classe social e o status, mais as pessoas consomem e obrigam-se a trabalhar mais com o que detestam:

[...] também o chefe do chefe do funcionário está maçado com os pedidos de crédito fastidiosos que anónimos igualmente fastidiosos fazem, não fosse o 
chalezito na neve, a casa num condomínio de luxo, a estada em Londres da filha mais velha, a especialização do filho do meio nos EUA, a mania do mais novo de ser artista, os carros de todos, as motos de todos, os cigarros e as bebidas de todos, as vaidades de todos, ah, os fins de semana com a amante em Nova lorque, e ninguém o obrigava a levantar-se todas as manhãs para se enfiar num gabinete com uma vista tão acanhada [...] (CARDOSO, 2012, p. 112-113).

As narrativas particulares ilustram a máxima "a quantidade de coisas de que as pessoas se convencem que precisam" (CARDOSO, 2012, p. 113) e expõem que, independentemente da posição social, a infelicidade reina, o topo não existe, o dinheiro e o status nunca são suficientes. Apesar das diferenças de classe, a insatisfação é comum a todas as pessoas que se deixam oprimir pela subserviência a um tipo de trabalho que não Ihes dá prazer, e que suportam pela necessidade de custear consumismos questionáveis. Violeta propõe reflexões sobre o absurdo naturalizado no mundo em que vivemos. Critica o consumismo, o capitalismo, a família tradicional portuguesa, enfim, os costumes de uma cultura e de uma sociedade.

Aspectos do caráter de Violeta são expostos nas máximas: uma mulher pessimista que julga. Além disso, a caracterização da personagem é feita através dessas máximas: pessimista, entediada, crítica, que aprecia utilizar seu tédio combinado a sua imaginação para supor coisas cruéis da vida das pessoas que observa. A máxima "não preciso saber de política, basta-me conhecer a natureza humana" (CARDOSO, 2012, p. 141) mostra-nos também que o pessimismo não necessariamente refere-se a um sistema político ou social, mas sim à natureza humana, apresentando caráter imoral. Através de Violeta, Cardoso propõe reflexões ao seu leitor quanto aos temas do romance. 
A escritora faz uso de uma camada superficial da estrutura da máxima, porque inverte o seu propósito na narrativa. Ao invés de utilizar a máxima para transmitir os valores éticos e morais de uma sociedade, Dulce Maria Cardoso a utiliza para desmascarar a realidade social portuguesa. Na divagação sobre os funcionários do banco e na referida máxima, a escritora, ao invés de reafirmar os valores sociais portugueses, os critica através de uma estrutura cuja finalidade é a reafirmação. Na narrativa sobre a vida do chefe do chefe do funcionário há, também, uma crítica à família tradicional e à religião. A menção à amante do chefe do chefe do funcionário denuncia o matrimônio corrompido, e o abuso de bebidas e cigarros não seria necessário se todo o trabalho, dinheiro e consumismo realmente trouxessem felicidade a este núcleo familiar. São indivíduos que fazem o que não gostam para manter um status de vida que não lhes traz felicidade.

A máxima "o povo vencido nunca mais será unido" (CARDOSO, 2012, p. 124) - uma inversão de "o povo unido jamais será vencido" - é repetida por Violeta enquanto conta o episódio em que ela e seus pais (passadistas) foram intimidados pelos revolucionários. A narrativa e a utilização da máxima contribuem para a caracterização da personagem, ou seja, denunciando sua perspectiva pessimista. Novamente, a máxima é utilizada, em Os meus sentimentos, de maneira invertida tanto no seu sentido quanto no seu propósito, pois, ao invés de reafirmar os valores sociais portugueses, ela questiona a relevância da Revolução dos Cravos.

A diferença entre Thurber e Cardoso, contudo, é que o primeiro, como propõe Carnes $(1988$, p. 326), utiliza suas fábulas para criticar a possibilidade de se obter ajuda de uma fábula para viver - ou de qualquer outro tipo de ajuda - demonstrando um aspecto 
niilista em sua obra. Apesar da personagem criada por Cardoso ser pessimista, imoral e descrente na humanidade, a escritora parece estar interessada em expor as sujidades da sociedade portuguesa através do discurso de Violeta, denunciando ao seu leitor aquilo que não deve ser esquecido sobre seu país. É por acreditar na humanidade que a escritora parece delinear sua crítica, convidando o leitor à reflexão e à ação.

A inversão das máximas é utilizada como ferramenta para desenvolver o projeto artístico da escritora nesse romance. Enquanto que em $O$ chão dos pardais ela utiliza a metaforização de personagens a fim desnudar a realidade social portuguesa, em Os meus sentimentos a escritora apresenta críticas sobre a família e a igreja - grandes pilares da cultura portuguesa - e questiona as verdades aparentes do contexto histórico representado na narrativa.

A empregada dos pais de Violeta, Maria da Guia, cujo propósito de vida era servir aos patrões, não perde a servidão nem sai da pobreza com o fim da ditadura salazarista. Ela profere a máxima "quando nos põem numa vida não sabemos ter outra" (CARDOSO, 2012, p. 187), referindo-se à continuidade de sua condição existencial. Violeta refere-se à personagem em suas divagações com a metonímia "farda", reduzindo-a ao seu antigo emprego que ainda define sua identidade social:

a farda que se esgarça num quarto alugado, não mais que cinco metros quadrados, quando por lá passo, o que faço raramente, só quando não tenho mesmo mais nada para fazer e me apetece falar com um tecido esfiapado, casas sem botões, duas mangas que se mexem com dificuldade / a menina desculpe isto ser tão acanhado / [...] a Maria da Guia que teve o azar de sobreviver aos donos [...] (CARDOSO, 2012, p. 190) 
Maria da Guia é o exemplo de que o propósito do 25 de Abril ainda está para ser alcançado, e que a revolução, apesar de ter derrubado o regime salazarista, não conquistou a melhora da desigualdade social.

As máximas "são tão maçadoras as lengalengas da revolução" (CARDOSO, 2012, p. 133) e "as revoluções são tão passageiras" (CARDOSO, 2012, p. 321) expõem a perspectiva de Violeta, instigando o leitor a refletir sobre as mudanças que a Revolução gerou na sociedade portuguesa, contribuindo para o desenvolvimento do projeto artístico no romance: desmascarar a realidade social portuguesa. Será que "as revoluções são tão passageiras" (CARDOSO, 2012, p. 321), por que a de Portugal não conseguiu contestar os três pilares que regem a sociedade: Estado, Igreja e família? Através da ironia e das máximas invertidas, Cardoso convida seu leitor à reflexão sobre o quadro político, histórico e social, bem como a posicionar-se dentro dele e a agir.

\section{CONSIDERAÇÕES FINAIS}

A inversão das máximas em Os meus sentimentos, de Dulce Maria Cardoso, pretende desenvolver o projeto artístico - proposto por Gonçalves Neto e Gama (2012, p. 1), tendo como corpus outro romance da escritora, $O$ chão dos pardais - também no romance que constitui nosso corpus. A extensão do projeto artístico a outras obras da escritora é mencionada pelos seus propositores. Ele consiste em desmascarar a realidade social portuguesa através de uma análise irônica e detalhada da mesma, buscando desmistificar o sujeito português e sua realidade e, ao mesmo tempo, propor uma reflexão ao seu leitor acerca dos problemas políticos e sociais de Portugal. 
A estrutura das máximas utilizada por Cardoso não abrange todos os aspectos do gênero. Máximas são proferidas por alguém mais velho, cujo caráter é confiável, como propõe Aristóteles (1982, p. 147), diferente de Violeta, imoral e pessimista; e porque a função das máximas, como propõe Cerdas (2011, p. 186), é transmitir os valores éticos e morais de uma sociedade, e as máximas de Cardoso questionam esses valores.

Logo, o uso de Dulce Maria Cardoso das máximas aproxima-se do uso de Thurber da fábula. Ambos utilizam a matéria original para colocar seus aspectos em questão: Thurber questiona, através da fábula, a função dessa como educadora; e Cardoso coloca em cheque, através da máxima, os valores éticos e morais de uma sociedade por ela transmitidos. Contudo, os escritores diferem-se na seguinte perspectiva: Thurber apresenta-se niilista; Cardoso apenas utiliza uma personagem pessimista e imoral para criar questionamentos acerca do período sócio-histórico representado na narrativa. Por querer fazer seu leitor refletir e agir frente aos problemas políticos e sociais portugueses, vemos uma fé na raça humana por parte da escritora da qual Thurber não compartilha.

Portanto, Dulce Maria Cardoso inverte a função original da máxima no discurso de Os meus sentimentos, questionando a validade do que é tido como verdade social e histórica, desnudando a sociedade portuguesa e convidando seu leitor à reflexão e à ação, desenvolvendo também nesse romance o seu projeto artístico. Afinal, como diz a epígrafe do romance: "Es el jardín de la Muerte que te busca y que te encuentra siempre... Es el jardín, que, sin saberlo, riegas com tu sangre" (LOYNAZ apud CARDOSO, 2012, p. 7). É o jardim da morte que sempre nos encontra e que regamos com nosso sangue. Retirada da novela Jardín - que narra o confinamento de Bárbara, mulher que, quando tenta sair do 
jardim, não se sente pronta pro mundo e volta a isolar-se nele -, a epígrafe pode ser interpretada metaforicamente: o jardim da morte é a nossa condição - psicológica, social, amorosa, física, interpessoal - e o sangue que o rega são as nossas atitudes. Como Violeta, que afirma "conheço o amor de ouvir falar" (CARDOSO, 2012, p. 48) e "nasceste para que eu pudesse experimentar o amor" (CARDOSO, 2012, p. 308-309), mas não consegue dizer à filha que a ama, a escritora convida-nos a parar de regar o que nos fere e a nutrir o que nos faz bem.

\section{REFERÊNCIAS}

ARISTÓTELES. Arte Retórica e Arte Poética. Rio de Janeiro: Ediouro, 1982.

BARTHES, R. La Rochefoucauld: reflexões ou sentenças máximas. Novos ensaios críticos / O grau zero da escrita. São Paulo: Cultrix, 1974.

BOM, G. Dulce Maria Cardoso: "O que me fez pensar no que estamos aqui a fazer foi o olhar de um cão". Entrevista. Diário de Notícias. 17 ago 2016. Disponível em: <http://www.dn.pt/portugal/entrevista/interior/dulce-maria-cardoso-o-que-me-fez-pensarno-que-andamos-aqui-a-fazer-foi-o-olhar-de-um-cao-5342457.html>. Acesso em: 15 mar 2018.

CARDOSO, D. M. O chão dos pardais. Lisboa: Tinta da China Portugal, 2014.

Os meus sentimentos. Rio de Janeiro: Tinta da China Brasil, 2012.

CARNES, P. The american face of Aesop: Thurber's Fables and Tradition. In: in fabula: essas on the relationship of the proverb and the fable. Paris: Lang, 1988. . Proverbia

CERDAS, E. A Ciropédia de Xenofante: um romance de formação na Antiguidade. São Paulo: Cultura acadêmica, 2011.

GONÇALVES NETO, N.; GAMA, A. P. F. Liquidez, reconfigurações e pluralidades: a representação identitária da sociedade portuguesa em Chão dos pardais, de Dulce Maria Cardoso. Anais da ABRALIC. Campina Grande, 2012. p. 1-7.

MONTEIRO-PLANTIN, R. S. ReVEL na Escola: Fraseologia e Paremiologia: para que ensinar, se todo o mundo sabe? ReVEL, vol. 15, n. 29, 2017. 
Artigo recebido em: 31 de maio de 2018. Artigo aprovado em: 06 de setembro de 2018. 